A N N A L E S Annales de Bretagne et des Pays de l'Ouest

\title{
Le pouvoir royal et les ligueurs de Tours
}

(1589-1598)

De la répression au pardon

Royal power and the Tours leaguers (1589-1598). From repression to forgiveness

\section{François Caillou}

\section{(2) OpenEdition}

\section{Journals}

Édition électronique

URL : http://journals.openedition.org/abpo/2669

DOI : $10.4000 / a b p o .2669$

ISBN : 978-2-7535-3304-2

ISSN : 2108-6443

\section{Éditeur}

Presses universitaires de Rennes

\section{Édition imprimée}

Date de publication : 30 décembre 2013

Pagination : 65-88

ISBN : 978-2-7535-3302-8

ISSN : 0399-0826

\section{Référence électronique}

François Caillou, «Le pouvoir royal et les ligueurs de Tours (1589-1598) », Annales de Bretagne et des Pays de l'Ouest [En ligne], 120-4 | 2013, mis en ligne le 30 décembre 2015, consulté le 19 avril 2019. URL : http://journals.openedition.org/abpo/2669; DOI : 10.4000/abpo.2669 


\title{
Le pouvoir royal et les ligueurs de Tours (1589-1598)
}

\author{
De la répression au pardon
}

\author{
François CAILLOU \\ Docteur en histoire moderne, membre associé du CERHIO, UMR 6258 \\ - université du Maine
}

Pendant longtemps, Tours a été considérée comme la cité loyaliste par excellence. En 1589, elle offre l'abri de ses murs à Henri III, en quête d'un asile sûr depuis l'assassinat du duc de Guise. Lorsque le souverain trépasse sous le couteau de Jacques Clément, elle s'incline immédiatement devant son successeur Henri de Navarre, pourtant très contesté à cause de ses convictions protestantes. De Tours, Henri IV fait sa base arrière, à partir de laquelle il entame la lente et difficile reconquête du royaume. Au cours de l'été 1589, quelques agitateurs tentent d'ouvrir la ville au duc de Mayenne, mais, découverts et neutralisés, ils quittent la scène de l'histoire aussi vite qu'ils y étaient entrés ${ }^{1}$. Il est maintenant bien établi que cette présentation des faits relève de la propagande. En 1589, Tours manque à trois reprises de basculer dans le camp de la Ligue à la suite de complots ourdis de l'intérieur par une organisation puissante et structurée, active dès $1584^{2}$. Qui étaient les ligueurs tourangeaux, aujourd'hui sortis de la mémoire collective? Pour répondre, il faut emprunter un chemin jalonné d'obstacles. Non seulement des sources capitales ont disparu, mais celles qui subsistent occultent partiellement la réalité, quand elles ne la déforment pas. Heureusement, des documents jusqu'ici peu exploités en révèlent beaucoup sur les adhérents du parti de l'Union. Ces éclaircissements apportés, on s'intéressera à l'audience de la Ligue à Tours. Pour cela, il faudra revenir sur les événements de la décennie 1589-1598, afin de vérifier si les ligueurs ont réellement cessé de

1. Depuis deux siècles, les ouvrages consacrés à l'histoire de la Touraine minimisent le phénomène ligueur. Le dernier en date ne fait pas exception, même s'il traite avec sérieux des guerres de Religion : Audin, Pierre, Petite histoire de la Touraine, La Crèche, Geste Éditions, 2011.

2. CAlllou, François, "L'essor et l'échec de la Ligue à Tours (1576-1589) ", Annales de Bretagne et des Pays de l'Ouest, t. 115, 2008, n 4, p. 31-53. 
représenter une menace ou s'ils continuent de susciter des troubles. Enfin, à la lumière des sources disponibles, on tentera de dresser un portrait de groupe des rebelles tourangeaux, pour mieux en cerner les motivations.

\section{De la difficulté d'étudier la Ligue à Tours}

Dans l'article premier de l'édit de Nantes, Henri IV ordonne que le souvenir des querelles du passé s'éteigne " comme de chose non avenuë ". Conformément à l'injonction royale, tout fut mis en œuvre à Tours pour gommer de la mémoire locale les épisodes gênants de l'histoire récente. C'est ainsi que les registres de délibérations du corps de ville des années 1586-1589 (jusqu'en mai), correspondant à une période de gestion municipale par des élus acquis à la Ligue, furent selon toute vraisemblance détruits ${ }^{3}$. Les rôles de ligueurs à expulser, à taxer et à désarmer dressés par le corps de ville sur ordre royal entre mai et août 1589 connurent le même sort. Pourtant, certains noms, en dehors de ceux du chef du mouvement et d'une demi-douzaine de ses séides pendus en août 1589, étaient connus des érudits d'Ancien Régime, preuve que d'autres sources avaient survécu. Dans son Abrégé chronologique et historique de la mairie de Tours, Louis Benoist de la Grandière - maire de Tours de 1768 à 1771 - dévoile l'identité de deux rebelles : le chanoine Alexandre Boismartin et le conseiller au présidial Cosme Goupil ${ }^{4}$. Ailleurs, il en évoque un autre en prenant soin de taire son nom : "Un particulier de cette ville, marchand, jus nomini parco, par rapport à sa famille qui existe encore à Tours, [qui] obtint des lettres de rappel de ban qui furent adressées au Parlement " (Jean Taschereau $)^{5}$. L'appartenance de certains mutins au clergé l'incite également à la réserve, comme en témoigne ce passage : «Un particullier dont on tait le nom, l'état et les fonctions qu'il avoit cy-devant remplies, pour l'honneur du corps duquel il avoit été membre " (allusion au chanoine de Saint-Martin René Le Tourneux) ${ }^{6}$.

Très tôt, un discours officiel célébrant le loyalisme tourangeau apparaît. Dans leurs lettres, les politiques qui contrôlent le corps de ville après l'épuration de celui-ci par Henri III en mai 1589 n'ont de cesse de rappeler au roi ce qu'il leur doit, avec des arrière-pensées intéressées. En récompense de leurs services, ils attendent des allègements de taxes, l'exemption du logement des gens de guerre, la confirmation des privilèges de la ville et la création d'une université, voire d'un parlement. Le roi ignore la plupart de ces doléances, se contentant de payer les édiles de bonnes paroles. Après

3. Ce phénomène n'est pas isolé. Les délibérations du corps de ville d'Angers antérieures à la tentative de coup de force du 20 février 1589 (à laquelle plusieurs édiles dont le maire Pierre Lechat avaient prêté leur concours) ont aussi disparu.

4. Benoist de La GRANDiERE, Louis, Abrégé chronologique et historique de la mairie de Tours, I, publié par G. Collon, dans Mémoires de la Société archéologique de Touraine, 1908, p. 331.

5. Ibidem, p. 316. Autre mention p. 324-325 : "Un des notaires de cette ville, dont je tais le nom " (Urbain Bretonneau).

6. Ibid., p. 310 . 
l'échec de la conjuration d'août 1589, il leur écrit pour les remercier du " bon devoir duquel vous avez usé à la conservation de notre ville de Tours en notre obéissance ". Quelques jours plus tard, il leur exprime encore sa gratitude : "Nous ne perdrons jamais la mémoire de vostre fidélité ${ }^{7}$. " La ville tira au final peu de bénéfices de sa loyauté ${ }^{8}$ et dut au contraire considérablement s'endetter pour répondre aux exigences du fisc royal ${ }^{9}$.

$\mathrm{Au} \mathrm{XVII}{ }^{\mathrm{e}}$ siècle, les chroniqueurs et les historiens prennent le relais pour souligner l'attachement des Tourangeaux à la dynastie régnante. Voici ce qu'écrit l'auteur anonyme des Annales de Touraine depuis l'origine de la ville de Tours jusqu'à l'année 1640 à propos des difficultés d'Henri IV à se faire reconnaître : "Néanmoins Tours parmi tant de divisions fut toujours constant $[\mathrm{sic}]$ et inébranlable dans la fidélité et l'attache qu'elle devait à son légitime roi, et quelques sollicitations qu'on lui put faire sous prétexte d'un faux zèle de religion, elle demeura ferme dans son devoir ${ }^{10}$. " Dans son Paradis délicieux de la Touraine, Martin Marteau évoque lui aussi la fidélité de ses compatriotes aux monarques désignés par la loi salique : "En effet les Tourangeaux sont naturellement si fidèles à leurs Roys, que la retraite de Charles VII à Tours, celle de son fils \& successeur Louys XI \& celles de Henry III \& IV pendant les troubles, en tesmoignent assez. » Plus loin, il qualifie même Tours d' " azile de la France ${ }^{11}$ ".

Les courtisans, hommes de lettres et gens du livre réfugiés sur les bords de Loire à l'appel d'Henri III ont contribué à la diffusion du mythe. L'un des plus éloquents, l'imprimeur Jamet Mettayer, écrit dans la préface d'une réédition de la coutume de Touraine « que Dieu, en ces si longs \& dangereux orages, \& temps si calamiteux, [...] a reservee \& conservee [cette province] nette \& pure de toute rebellion \& felonnie, pour se servir d'elle, comme fidelle de tout temps à ses Roys ". Il dépeint la ville de Tours comme " un vray rampart, un fort asseuré, \& asyle opportun, pour y recueillir, heberger, \& loger [les] affectionnez serviteurs de Dieu, du Roy nostre Sire, de ceste Coronne " $(1591)^{12}$. Paradoxalement, la légende a également été propagée

7. Lettres historiques des archives communales de la ville de Tours depuis Charles VI jusqu'à la fin du règne de Henri IV, 1416-1594, publiées par Victor Luzarche, Tours, Mame, 1861, p. 134-136 et 140-142.

8. Les Tourangeaux n'obtinrent ni parlement, ni université. En récompense de leur fidélité, Henri IV leur octroya tout de même en 1594 deux muids de sel, francs de gabelle, à prendre au grenier de Tours, convertis en 400 écus; un don confirmé par Louis XIII en 1633 (renseignement fourni par Claude Petitfrère).

9. Un siècle plus tard, elle ne s'en était toujours pas remise. PETITFRERE, Claude, " Les embarras financiers d'un corps de ville : l'exemple de Tours au Grand Siècle (vers 15891717)", dans Pourvoir les finances en province sous l'Ancien Régime. Journée d'études tenue à Bercy le 9 décembre 1999, Paris, CHEFF, 2002, p. 51-83.

10. Annales de Touraine depuis l'origine de la ville de Tours jusqu'à l'année 1640, Bibl. mun. de Tours, Ms 1216 bis, f 782 (copie réalisée en 1866 du Ms 1216, aujourd'hui disparu).

11. Marteau, Martin, Le paradis délicieux de la Touraine..., $2^{\mathrm{e}}$ éd., Paris, chez Louis de La Fosse, 1661, $1^{\text {re }}$ partie, p. 34 et 41.

12. Cité par AugerEAu, Laurence, La vie intellectuelle à Tours pendant la Ligue (1589-1594), Thèse de lettres dact., Université de Tours, 2003, 3 vol., t. 2, p. 674. 
par les ligueurs eux-mêmes, ce qui n'a pas peu contribué à lui donner des airs de vérité d'Évangile. Dès le printemps 1589, une brochure ligueuse accuse : en ouvrant leurs portes à Henri III, les Tourangeaux ont cédé à de "mondaines considérations " et sont " tombés aux labyrinthes, d'où ilz ne se pourront pas aisément depestrer ». La ville, lit-on, grouille à présent d'hérétiques au service du roi de Navarre qui s'y pavanent avec arrogance, tandis que les " pauvres catholiques" sont victimes d'extorsions et de mauvais traitements. Ses habitants " regrettent (mais en vain) la misérable condition où ils ont esté réduits par leur négligence et lascheté ${ }^{13}$ ". Pour les partisans des Guise, Tours est désormais la ville des politiques par excellence, dont le sort préfigure celui que pourrait connaître le royaume si d'aventure un hérétique montait sur le trône ${ }^{14}$. Les guerres de Religion terminées, les voyageurs étrangers ont à leur tour repris l'antienne, lui donnant une portée internationale. Thomas Platter, qui découvre Tours en 1599, assure qu'" aujourd'hui encore, la ville est très fidèle au roi de France et elle ne lui a jamais fait faux bond ${ }^{15}$ ". La prétendue fidélité des Tourangeaux à leurs rois légitimes devient en l'espace de quelques décennies un lieu commun mentionné dans presque tous les guides de voyage, tels L'Ulysse françois de Louis Coulon (1643) ou Le guide fidelle des étrangers dans le voyage de France d'Alcide de Saint-Maurice $(1672)^{16}$. La lecture des chroniques et mémoires de l'époque, en particulier de l'Histoire universelle de JacquesAuguste de Thou, bon connaisseur des événements tourangeaux - il fut l'un des réfugiés parisiens fidèles au roi qui se replièrent à Tours ${ }^{17}$ - laisse pourtant une toute autre impression. Loin d'être acquise au roi, la capitale de Touraine était en 1589 partiellement passée sous le contrôle du parti de l'Union, en particulier les quartiers populaires de l'ouest. Si Tours resta dans le giron royal, c'est parce que le pouvoir, après avoir longuement tergiversé, réprima sans ménagement la contestation en août 1589.

Les chroniques présentent le défaut de ne mentionner que rarement les acteurs " mineurs " des guerres de Religion : seuls les « Grands " y apparais-

13. Lettre d'un gentilhomme françois, escrites à Tours, le 29 avril 1589, envoyées à ung seigneur catholique de la ville de Paris (signé F. D. L.), Paris, Rolin Thierry, 1589, p. 11-12.

14. Dans la même veine, signalons la Lettre d'un gentil-homme françois, escrites [sic] à Tours le 29 avril 1589, envoyées à ung seigneur catholique de la ville de Paris, contenant au vray l'estat et succez des entreprinses de Henry de Valois contre l'Eglise catholique et la tyrannie par luy exercee sur les catholiques de Tours, pour servir d'exemple aux villes qui le receuvront, Tolose, Impr. des Colomiez, 1589 (signée F. D. L.); la Copie des lettres d'un politicque de Tours envoyées à ung politicque de la ville de Roüen (signées P. D., 6 janvier 1590), Lyon, 1590; La dispute d'un catholique de Paris contre un politique de la ville de Tours, Paris, R. Nivelle et Rolin Thierry, 1591.

15. L'Europe de Thomas Platter. France, Angleterre, Pays-Bas, 1599-1600 (Le siècle des Platter III), texte présenté par Le Roy Ladurie, Emmanuel, Paris, Fayard, 2006, p. 56.

16. Coulon, Louis, L'Ulysse françois, ou Le voyage de France, de Flandre et de Savoye : contenant les plus rares curiosités des pays, la situation des villes, les mours..., Paris, G. Clouzier, 1643, p. 387; SAINT-MAURICE, Alcide de Bonnecase, sieur de, Le guide fidelle des étrangers dans le voyage de France, Paris, chez Estienne Loyson, 1672, p. 105.

17. Thou, Jacques-Auguste de, Histoire universelle depuis 1543 jusqu'en 1607, Londres, 1734,16 volumes. 
sent en pleine lumière. Heureusement, d'autres sources subsistent. La principale est constituée des registres de délibérations du corps de ville de 1589 à 1598. Entre 1591 et 1594, la municipalité délivre des autorisations de réinstallation aux ligueurs ayant purgé une peine de bannissement ou désireux de tirer parti des édits de réduction des villes de Poitiers et d'Orléans (1594) où plusieurs opposants à Henri III et à Henri IV avaient trouvé refuge, ce qui permet de dresser une première liste de rebelles. Une autre source fondamentale, non exploitée jusqu'ici, est un registre de comptes de la Chambre du domaine chargée d'affermer les biens des ligueurs saisis par le souverain ${ }^{18}$. Grâce à elle, d'autres noms surgissent. En outre, le fichier d'état civil ancien des Archives municipales de Tours et les minutiers des notaires - qu'il faut sonder, faute de répertoires - fournissent des informations précieuses sur le cursus professionnel et le milieu familial des mutins ${ }^{19}$. Enfin, les registres du parlement de Paris contiennent des données essentielles sur les acteurs des complots de 1589 et la répression menée contre les sympathisants de la Ligue après cette date, même s'ils livrent peu de noms.

\section{9-1598 : dix années d'agitation}

L'existence à Tours d'un mouvement ligueur est attestée dès 1584-1585. Son fondateur probable et chef incontesté, Gilles Duverger, appartient à ce que l'on peut nommer le parti guisard. Avocat de formation, il entre vers 1560 au service de la reine Marie Stuart, duchesse douairière de Touraine, nièce du duc François de Guise et du cardinal de Lorraine. De simple conseiller (1563), il se hisse au rang de chancelier de la reine (1575). Grâce à ses protecteurs lorrains, il obtient l'office de président du siège présidial de Tours, qu'il cumule avec celui de lieutenant général à partir de 1584 . L'année suivante, il rencontre à Tours Nicolas Ameline, émissaire du duc de Guise. Il fédère autour de lui des Tourangeaux viscéralement attachés au culte catholique qui refusent de voir un " hérétique " accéder au trône de France. En 1588, le cahier de doléances du tiers État de Touraine, inspiré des statuts synodaux de l'archevêque Simon de Maillé, est l'œuvre d'une quinzaine de ligueurs avérés ou sympathisants, dont Duverger en personne. La même année, Duverger est désigné député du tiers État aux États généraux de Blois et peu de temps après élu maire de Tours. L'homme est à l'origine des trois séditions de janvier-février, mai et août 1589. Lors des deux dernières, il tire les ficelles de l'extérieur, car il a eu la prudence de quitter la ville avant l'arrivée du roi. Les trois conjurations ont des caractéristiques communes. Initiées en période de faiblesse supposée du pouvoir royal, en coordination avec les armées rebelles qui font de la prise de Tours un objectif prioritaire, elles débutent par une campagne de propagande orchestrée par les éléments les plus fanatiques du clergé, qui prophétisent

18. Bibliothèque nationale de France (dorénavant BnF), Nouv. acq. fr. 393.

19. On ne peut que déplorer la disparition des minutes du notaire ligueur Urbain Bretonneau et de la quasi-totalité des actes passés par Perdriau, notaire de la paroisse Saint-Saturnin dont l'étude était fréquentée par des ligueurs de premier plan. 
un "bain de sang " dont les " bons catholiques " seraient les victimes en cas de prise de contrôle de la ville par les forces du roi de Navarre. L'objectif est de soulever un maximum d'habitants des faubourgs et de profiter du désordre ambiant pour ouvrir les portes de la cité à des troupes amies. Le complot d'août est plus ambitieux encore, puisque l'arrestation (voire l'assassinat) de plusieurs membres du Conseil du roi est programmée. Les sources conservées, presque toutes postérieures au mois d'août 1589, ne permettent qu'exceptionnellement de préciser à quel complot tel ligueur est associé. Concernant le premier, aucun nom n'est connu, si l'on excepte celui de Duverger. En mai, sont essentiellement impliqués des individus haut placés dans la hiérarchie sociale pour la plupart membres du corps de ville, que le roi dissout et réorganise : Louis Gingot, conseiller au présidial, Pierre Chapelain, président de l'élection, François Joubert, greffier du corps de ville, son fils Nicolas Joubert, receveur des tailles, Jean Bergerat, trésorier des turcies et levées... Les origines des comploteurs arrêtés et condamnés au mois d'août sont composites, ce qui montre que la direction du mouvement a été partiellement décapitée au printemps. Si le conseiller au présidial Marc Gléteraye et le chanoine de Saint-Martin René Le Tourneux figurent parmi les conjurés, on trouve aussi dans le lot un sergent de milice bourgeoise, un receveur des douanes et un huissier. Fait nouveau, un étranger à la ville a joué un rôle central dans le complot : le cordelier René Marier, en tant qu' "envoyé spécial " de Duverger. Les conjurations échouent toujours pour les mêmes raisons : la fermeté des forces royales - le gouverneur par intérim Gilles de Souvré et les principaux capitaines -, que les ligueurs tentent en vain de circonvenir; et la puissance du courant adverse, celui des "politiques", dominé par les officiers du bureau des finances, qui exerce une emprise solide sur les quartiers centraux de la ville ${ }^{20}$.

En août 1589, les autorités prennent des mesures draconiennes pour prévenir toute nouvelle " entreprise " des rebelles. Le nombre de militaires stationnés en ville augmente, au grand dam de la population qui doit leur fournir le gîte. Outre les 50 chevau-légers et les 30 arquebusiers formant la garde habituelle du gouverneur Gilles de Souvré et les 600 soldats (dont 200 Suisses) appelés en renfort en juin, Tours accueille deux compagnies commandées par le sieur de Parabère. Environ mille hommes de guerre assurent la protection de la cité fin $1589^{21}$. Les édiles font procéder à des travaux de protection (réparation des ponts, remise en état des murailles, renforcement des portes, creusement de tranchées), poursuivant le programme entamé à l'arrivée d'Henri III ${ }^{22}$. Jusqu'en 1595, des dizaines

20. Pour plus de détails sur les événements de 1584-1589, cf CAILLou, François, «L'essor et l'échec..." ", art. cit., p. 31-53.

21. Woodland, Sandrine, “ Tours, ville royale » au temps de la Ligue (1589-1595), Maîtrise dact., Université de Tours, 2003, 2 vol., t. 1, p. 38.

22. Ibidem, p. 20-25. De mars à juillet, la municipalité a employé l'ingénieur italien Urbino, appelé spécialement de Blois " pour la direction et devis des fortifications " (Arch. mun. Tours, CC t. 98, f ${ }^{\circ}$ ). 
d'hommes œuvrent quotidiennement à la consolidation de l'enceinte de la ville $^{23}$. Surtout, les autorités tentent de contrôler les allées et venues, ce qu'elles avaient négligé jusqu'ici. Par une ordonnance d'août $1589^{24}$ confirmée par l'arrêt du Conseil du 15 novembre 1590 " pour continuer l'establissement de l'ordre qui est nécessaire pour la garde et seureté de ceste ville ", Gilles de Souvré instaure des règles strictes : fouille au corps à l'entrée en ville, dépôt des armes au capitaine en faction à la porte, obligation de présenter un billet signé du greffier de l'hôtel de ville pour obtenir une chambre en hôtellerie, injonction aux cabaretiers et hôteliers de remettre chaque soir au maire une liste de leurs clients, visite par les quarteniers des ateliers des artisans pour s'informer des serviteurs et compagnons étrangers qu'ils emploient, fermeture des portes de la cité de 17 heures à 7 heures du matin, réorganisation de la garde bourgeoise. Le courrier fait l'objet d'une surveillance renforcée : l'arrêt de 1590 prévoit l'établissement d'un bureau où l'on examinera les lettres et les paquets sortant de Tours ${ }^{25}$. La municipalité s'efforce de seconder les efforts du gouverneur. Tout commerçant ou artisan originaire d'une zone rebelle souhaitant s'établir à Tours doit en formuler la demande aux élus et se soumettre à une enquête préalable $^{26}$. Régulièrement, les édiles font procéder à des vérifications d'identité (17 septembre et 9 novembre 1589, 3 janvier 1590 et 18 mars 1591) ${ }^{27}$ et à des perquisitions de maisons ou de couvents (31 janvier, 23 mars et 30 avril 1590). Ils font aussi appliquer la législation royale sur le contrôle du courrier : le 21 mars 1592, ils convoquent et tancent vertement l'épouse d'un magistrat du Parlement qui a fait porter des lettres à Poitiers, ville ligueuse ${ }^{28}$. Parallèlement, le Parlement prend en charge la lutte contre les prêtres désobéissants et les libellistes clandestins. Le 11 septembre 1589, il rend un arrêt "sur le devoir des prédicateurs ". Le 19, il blâme tous ceux qui ont loué l'assassinat du roi ${ }^{29}$. Le 21 juillet 1589, il avait déjà fait interdire la vente et l'impression des livres et traités sur "le faict de la Relligion " sans examen préalable par deux théologiens " fidelles serviteurs du Roy". Dans un autre arrêt du 17 avril 1590, il menace de mort toute personne ayant distribué des placards portant atteinte à la religion catholique ou sur laquelle on aurait saisi ce genre de document. Le 14 février 1591, il défend la diffusion sans autorisation officielle des livres, discours et libelles,

23. Arch. mun. Tours, BB $24, \mathrm{f}^{\circ} 375 \mathrm{r}^{\circ}-472 \mathrm{v}^{\circ}$ : registre des délibérations relatives aux fortifications, 1591-1595.

24. Mentionnée dans la délibération du 27 août 1589 . Ibid., $\mathrm{f}^{\circ} 71 \mathrm{v}^{\circ}$.

25. Arch. mun. Tours, EE 8, dossier 3 (arrêt imprimé en cinquante exemplaires). Transcription dans WoodLand, Sandrine, op. cit., t. 2, p. 7-10.

26. Arch. mun. Tours, BB 24, f 549 r $^{\circ}, 14$ août 1591 (Claude Depains, ouvrier de la monnaie, de Troyes); $\mathrm{f}^{\circ} 574 \mathrm{r}^{\circ}, 26 / 10 / 1591$ (Philippe Salomon, facteur d'un marchand caennais, qui souhaite établir un magasin de beurre et de suif au faubourg Saint-Symphorien); BB 25, f ${ }^{\circ}$ 305-306, 8/10/1593 (Roland Allain, maître savetier, de Paris); f ${ }^{\circ} 333 \mathrm{r}^{\circ}, 15 / 1 / 1594$ (Simon Singlin, marchand, de Paris), etc.

27. Arch. mun. Tours, BB 24, $\mathrm{f}^{\circ} 84 \mathrm{v}^{\circ}, \mathrm{f}^{\circ} 122 \mathrm{r}^{\circ}, 146 \mathrm{v}^{\circ}$ et $507 \mathrm{r}^{\circ}$.

28. Arch. mun. Tours, BB $25, \mathrm{f}^{\circ} 70 \mathrm{v}^{\circ}$.

29. BnF, Ms fr. $21306, \mathrm{f}^{\circ} 35 \mathrm{r}^{\circ}-37 \mathrm{v}^{\circ}$ et $39 \mathrm{r}^{\circ}-44 \mathrm{r}^{\circ}$. 
sous peine pour les contrevenants " d'estre puniz comme perturbateurs du repos public ${ }^{30}$ ".

Cette politique a donné des résultats. Les registres de délibérations municipales font état à plusieurs reprises de l'interpellation d'individus louches : trois mariniers d'Orléans démunis de passeport qui prétendaient se rendre à Nantes pour y charger du sel le 10 août 1591, un homme arrivé d'Orléans où il était soi-disant retenu prisonnier le 2 octobre 1591, une douzaine de colporteurs du Dauphiné sans passeport le 4 avril 1592, un petit groupe de marchands drapiers orléanais se présentant comme des exilés politiques le 12 août $1592^{31}$. Pour s'assurer de la sincérité des Orléanais, nombreux à demander asile à Tours, les édiles font parfois appel à des réfugiés ayant quitté cette ville après son passage à la Ligue, qui jouent ainsi le rôle d'informateurs $^{32}$. Le 15 mai 1591, les autorités capturent un ligueur infiltré, fils du cierger Marin Huart, trouvé caché dans la maison de son père ${ }^{33}$.

Cependant, en dépit d'une vigilance accrue, la Ligue menace toujours, notamment dans les environs de Tours où l'insécurité ne diminue pas avant 1594. Les incursions d'espions et d'éclaireurs aux ordres du maréchal de La Châtre, chef des ligueurs de l'Orléanais, montrent que le risque d'une offensive contre la ville n'a pas disparu après 1589, même si deux soldats rebelles arrêtés près de Saint-Martin-le-Beau, interrogés sur ce sujet en janvier 1593, prétendent que le projet n'est plus d'actualité ${ }^{34}$. Le plus préoccupant est qu'ils peuvent compter sur la complicité d'habitants du plat-pays. En juillet 1593, un détachement de l'armée royale capture un laboureur et un forgeron de Vallières, soupçonnés d'avoir servi de guides à des ligueurs ${ }^{35}$. Le danger émane moins des troupes régulières que des gens de guerre en rupture de ban opérant pour leur propre compte. Aux confins de la Touraine existent de petites forteresses à partir desquelles des bandes de soudards lancent des raids en direction de Tours et des villes du Val de Loire fidèles à Henri IV. En janvier 1590, les troupes royales interceptent à proximité de Pont-de-Ruan sept à huit soldats responsables d'une série de pillages aux environs de Tours ${ }^{36}$. En août de la même année, le maire propose la constitution d'une compagnie de combattants volontaires qui pourrait s'associer à un détachement de cuirassiers et d'arquebusiers à cheval, " pour aller ensemblement à la guerre ou se départir selon que la nécessité le requeroit pour la conservation du plat pays des environs de lad. ville, seureté des habitans [...]

30. Boulay DE LA MEURTHE, Alfred, « Notes sur des imprimeurs et libraires de Tours pendant la Ligue ", Bulletin de la Société archéologique de Touraine, t. 13, 1901-1902, p. 563-571. Sur l'action du Parlement, cf DAUBRESSE, Sylvie, " Les parlementaires parisiens à Tours face à la rébellion (fin 1590-début 1591) ", dans DAussy, Hugues, PITOu, Frédérique (dir.), Hommes de loi et politique (XVI -XVIII siècles), Rennes, PUR, 2007, p. 53-73.

31. Arch. mun. Tours, BB 24, $\mathrm{f}^{\circ} 543 \mathrm{r}^{\circ}$ et $565 \mathrm{r}^{\circ}$; BB 25, $\mathrm{f}^{\circ} 77 \mathrm{r}^{\circ} \mathrm{v}^{\circ}, 134 \mathrm{r}^{\circ} \mathrm{v}^{\circ}$ et $140 \mathrm{r}^{\circ}$.

32. C'est le cas lors de l'arrestation des trois mariniers.

33. Arch. mun. Tours, BB 24, $\mathrm{f}^{\circ} 524 \mathrm{r}^{\circ}$.

34. Arch. mun., BB 25, $\mathrm{f}^{\circ} 214 \mathrm{v}^{\circ}-215 \mathrm{r}^{\circ}$ (7 janvier 1593).

35. Arch. mun., BB 25, $\mathrm{f}^{\circ} 284 \mathrm{v}^{\circ}-285 \mathrm{r}^{\circ}$ : délibération du 28 juillet 1593.

36. Arch. mun. Tours, BB 24, $\mathrm{f}^{\circ} 148 \mathrm{r}^{\circ} \mathrm{v}^{\circ}$ : délibération du 9 janvier 1590 . 
et de tous autres bons subjectz et serviteurs de Sa majesté qui en sortent et y arrivent ". D'après lui, la mesure est nécessaire pour mettre un terme aux agissements des rebelles qui « courent journellement ès environs de lad. ville et emmènent prisonniers sans aulcune résistance, à la totalle ruine [...] des bons subjectz de Sa Majesté ". Le corps de ville accueille favorablement la proposition et envisage même d'effectuer un emprunt pour couvrir les frais, mais l'idée semble avoir déplu au Conseil ${ }^{37}$. En 1593, les routes de Touraine demeurent toujours aussi peu sûres. En juillet, le corps de ville est avisé de la présence près de Château-Renault d'une troupe de 120 cavaliers rebelles qui ravage la campagne ${ }^{38}$. L'année 1593 est également marquée par le démantèlement d'une bande de gens de guerre de l'Orléanais qui sévissait sur la rive droite de la Loire depuis 1589 . Une première fois capturé, leur chef, un nommé Bourgneuf, avait été relâché sur ordre de Souvré contre la promesse de ne plus combattre l'armée royale à moins de douze lieues de Tours. Or, le 3 janvier, le corps de ville apprend qu'il a été surpris avec ses hommes à trois lieues de la ville. Rapidement, des témoignages affluent sur les exactions de la bande : vols, prises d'otages et surtout meurtre d'un jeune artisan. Bourgneuf ne peut plus faire état de sa qualité de soldat au service du maréchal de La Châtre pour échapper la peine de mort : il est exécuté avec ses complices en mars $1593^{39}$.

En ville, le retour au calme est tout relatif, d'autant que certains éléments du clergé n'ont pas renoncé à exciter les foules. En 1590, au lendemain de la Pentecôte, le premier président du Parlement dénonce un curé de paroisse : "Hier, assistant à la prédication du curé [de] Sainct Saturnin, il luy ouit tenir des propositions fort séditieuses, entre autres que le peuple debvoit estre uny pour la relligion catholique et que la noblesse se bandoit contre l'Eglise ". Chose scandaleuse, « il n'avoit point prié Dieu pour la conservation du Roy ny prospérité de ses affaires ". Le magistrat met en garde contre le danger représenté par ces prédicateurs, qui par leur "domageable et pernicieuse violence [ont] ruiné Paris et tant d'autres villes ${ }^{40}$ ". Saint-Saturnin, paroisse de résidence des principaux meneurs de la Ligue en 1588, était depuis de nombreuses années un foyer de lutte contre "l'hérésie ". En 1572, juste après la Saint-Barthélemy, le curé Martin Arnault avait publié un Cathéchisme ou Doctrine abrégée pour faire profession de foi, maintenir les catholiques en leur religion et réduire les errants en la foi à l'union de l'Église universelle ${ }^{41}$. Le nom du curé emprisonné en 1590 est connu par une autre source : il s'agit du cordelier François Gisquet, docteur en théologie, installé en 1589 en lieu et place du chanoine martinien Louis Huau, lequel avait succédé vers 1586 à René Le

37. Arch. mun. Tours, BB $24, \mathrm{f}^{\circ} 247 \mathrm{r}^{\circ} \mathrm{v}^{\circ}$ : délibération du 16 août 1590 . WoodLAND, Sandrine, mém. cit., t. 1, p. 72.

38. Arch. mun. Tours, BB $25, \mathrm{f}^{\circ} 285 \mathrm{r}^{\circ} \mathrm{v}^{\circ}$ : délibération du 28 juillet 1593.

39. WoodLand, Sandrine, op. cit., t. 1, p. 78-84. La sentence déclencha l'ire du corps de ville d'Orléans, qui envoya plusieurs lettres menaçantes à celui de Tours.

40. Arch. nat., $\mathrm{X}^{1 \mathrm{~A}} 9232, \mathrm{f}^{\circ} 50 \mathrm{r}^{\circ}$ : arrêt du 11 mai 1590.

41. GRANDMAISON, Louis de, notice sur Martin Arnault dans Bulletin de la Société archéologique de Touraine, t. 26, 1935-1937, p. 181. Arnault était également chanoine de Saint-Martin. 
Tourneux ${ }^{42}$. Beaucoup de prédicateurs favorables à la Ligue étaient à l'instar de Gisquet membres d'un ordre mendiant. Les autorités le savaient et se méfiaient de ces religieux. Déjà, en juillet 1589, le corps de ville avait ordonné la perquisition des couvents des carmes et des jacobins, la confiscation des échelles trouvées sur place et l'expulsion de deux cordeliers " arrivez en lad. ville soubz le passeport de Chessé leur principal ${ }^{43}$ ". L'assassinat d'Henri III par un moine jacobin ne fit rien pour lever les soupçons pesant sur eux. En 1593, Gilles de Souvré fait expulser de la ville le carme Louis Gendron, auteur d'un sermon de Pentecôte " contre les fauteurs des hérétiques " (expression visant les politiques) ${ }^{44}$. Des mesures semblables sont également prises à l'encontre du prieur des jacobins et " autres prédicateurs ". Une autre communauté manifeste son opposition à Henri IV : les minimes du Plessis-lèsTours. Apprenant qu'ils refusent de dire les prières usuelles pour la santé du roi et de chanter l'exaudiat, le Parlement leur ordonne par arrêt du 28 juin 1591 de se conformer à l'usage, sous peine de privation de leur pension et de punition corporelle. En même temps, il place sous sa protection l'un des religieux, Jacques Pichonneau, menacé de mort par ses confrères pour avoir prêché l'obéissance due au souverain ${ }^{45}$. Le cas n'est pas isolé : d'autres religieux ayant pris fait et cause pour le roi bénéficient du soutien des autorités. Le jacobin Beaugeard, par exemple : le 26 octobre 1591, le corps de ville lui fait présent de 12 écus pour le récompenser de ses sermons et l'encourager à continuer ${ }^{46}$. La suspension de leur pension ne parvient pas à ramener les minimes à de meilleurs sentiments. Le 16 septembre 1591, le Parlement apprend « que le minime qui presche à Sainct Martin a depuis quelques jours faict des prédications [...] tendantes à sédition " ${ }^{47}$. Plus grave encore, en septembre 1592 le minime Étienne Habert est traduit en justice pour n'avoir pas dénoncé un raid de ligueurs contre le château du Plessis-lès-Tours et avoir " aidé aux meurtres et voleries par eux commis ". Il est condamné à mort le 8 octobre suivant ${ }^{48}$. Le frère Asselin, provincial de l'ordre, est quant à lui mis hors de cause après un long interrogatoire ${ }^{49}$.

42. Arch. dép. d'Indre-et-Loire, G 1024 : inventaire des titres, domaines et rentes de la fabrique de Saint-Saturnin, 1727, p. 48-50.

43. Arch. mun. Tours, BB 24, $\mathrm{f}^{\circ} 41 \mathrm{r}^{\circ}, 41 \mathrm{v}^{\circ}$ et $48 \mathrm{r}^{\circ}$ : délibérations des 12 et 18 juillet 1589.

44. MARTEAU, Martin, op. cit., deuxième partie, p. 26-27. Il est placé sur un bateau en partance pour Nantes.

45. Arch. nat., $\mathrm{X}^{1 \mathrm{~A}} 9234, \mathrm{f}^{\circ} 107 \mathrm{r}^{\circ}-108 \mathrm{r}^{\circ}$.

46. Arch. mun. Tours, BB 24, $\mathrm{f}^{\circ} 573 \mathrm{r}^{\circ}$. Il s'agit sans doute d'Isaac Beaugeard, qui succède à François Gisquet comme curé de Saint-Saturnin (avec l'appui du pouvoir?) : Arch. dép. d'Indre-et-Loire, G 1024 , p. 50.

47. Arch. nat., $\mathrm{X}^{1 \mathrm{~A}} 9234, \mathrm{f}^{\circ} 428 \mathrm{r}^{\circ}$.

48. BnF, Ms fr. $21306, \mathrm{f}^{\circ} 100 \mathrm{r}^{\circ} \mathrm{v}^{\circ}$ : arrêt du 8 octobre 1592 . Un ordre de prise de corps est lancé contre deux ligueurs, Catherin Boltin et Jean Rousseau dit le capitaine de la Roussilière, de Saint-Épain. Dans son recueil historique sur l'ordre des minimes de saint François, Jacques Rosier nie farouchement l'implication d'Étienne Habert, victime selon lui d'accusations calomnieuses : Arch. dép. d'Indre-et-Loire, H 695 (en latin), p. 257 (merci à Christophe Maillard qui m'a signalé cet ouvrage).

49. Augereau, Laurence, op. cit., t. 1, p. 155. 
Les mesures décrétées pour assurer l'ordre à Tours n'ont pas eu l'efficacité escomptée. Malgré les arrêts du Parlement, des placards clandestins circulent toujours, comme l'Advertissement au Roy a present regnant pour ne se destyr de sa relligion, signalé au corps de ville en octobre 1589. Dans son arrêt du 17 avril 1590, le Parlement mentionne Le grand pardon general pour tous Crestiens, opuscule rempli de " blasphesmes et impietez " contre Dieu et la religion catholique ${ }^{50}$. Jusqu'en 1594, les "mauvais propos " et autres provocations restent monnaie courante. Peu de temps après la mort du cardinal de Bourbon (mai 1590), Robert Goussu, maître de musique de la collégiale de Saint-Martin, invité à " composer quelque chose en musique à la louange du Roy ", réplique que " monsieur le cardinal estant mort, il ne recongnoissoit pour Roy ung haeretique ${ }^{51}$ ". En mars 1591, le parlement fait arrêter deux compagnons cordonniers coupables d'avoir crié "Vive la Ligue! » en pleine rue. Au mois de mai suivant, un habitant du faubourg de La Riche est incarcéré pour des paroles séditieuses et insultes envers le roi et le cardinal de Bourbon, respectivement qualifiés d'hérétique et d'apostat. En août 1592, un enfant est trouvé dans la rue portant une banderole frappée de la croix de Lorraine, emblème guisard. En août 1593, un artisan se permet des commentaires désobligeants au passage de membres de la cour se rendant à une procession organisée pour célébrer la conversion du roi $^{52}$. Les infiltrations de ligueurs se poursuivent, comme on l'a noté avec le fils de Marin Huart en 1591. Signalons encore l'arrestation, en juillet 1593, de Julien Le Mercier, soldat au service de Boisdauphin, chef de la Ligue en Anjou et dans le Maine ${ }^{53}$.

L'évasion du jeune duc de Guise, le 15 août 1591, constitue une preuve du maintien à Tours après 1589 d'un parti ligueur structuré, étroitement lié aux rebelles orléanais. Cet épisode spectaculaire ayant fait l'objet d'un long récit par Jacques-Auguste de Thou et surtout Palma Cayet ${ }^{54}$, il s'agit simplement ici de mettre en évidence les éléments démontrant l'existence d'une filière ligueuse ayant facilité la fuite du duc. Notons tout d'abord que celui-ci était parvenu à entrer en contact avec La Châtre par l'intermédiaire d'un laquais laissé imprudemment libre de ses mouvements. C'est en concertation avec le maréchal que fut choisie la date d'évasion ${ }^{55}$. Le duc s'échappe au moyen d'une corde que des complices lui ont fait passer, dissimulée dans une chemise de retour du blanchissage. Pour quitter la ville, il n'emprunte pas n'importe quel parcours : au lieu de se diriger

50. Woodland, Sandrine, op. cit., t. 1, p. 66-67.

51. En réaction, les "diables de Tours ", c'est-à-dire les partisans d'Henri IV, l'obligent à faire amende honorable et le chassent de la ville; il deviendra maître de musique à Mantes. Le Pelletier, Sébastien, Histoire (1579-1592), Genève, Droz, 2006, p. 286.

52. AugEREAU, Laurence, op. cit., t. 1, p. 162-163.

53. WoOdLAND, Sandrine, op. cit., t. 1, p. 70.

54. Thou, Jacques-Auguste de, op. cit., t. 11, p. 380-382. DeshoulièRES, " Itinéraire du duc de Guise après son évasion [d'après Palma Cayet] ", Bulletin de la Société archéologique de Touraine, t. 14, 1903-1904, p. 30-31.

55. Discours véritable de la délivrance miraculeuse de Monseigneur le duc de Guyse nagueres captif au chasteau de Tours, Bruxelles, chez Velpius, 1591, p. 13. 
vers l'est de la ville où se trouve la porte la plus proche (le pont sur la Loire étant trop bien gardé), il gagne avec deux valets le faubourg de La Riche, majoritairement acquis à la Ligue. Sur place, l'auteur des Annales de Touraine rapporte qu'un boulanger le reconnut (la rencontre était-elle fortuite?) et lui remit une monture sur laquelle il franchit le Cher. L'émissaire de La Châtre qui vint à sa rencontre pour le mener vers une escorte de cavaliers n'était autre que l'huissier Corbeau, un fidèle de Gilles Duverger qui avait échappé à l'arrestation en août 1589 et rejoint les ligueurs d'Orléans ${ }^{56}$. De Thou soupçonne l'entourage de la reine douairière Louise de Savoie d'avoir joué un rôle dans l'opération : des lettres de dames de sa cour auraient été saisies à Tours, dans lesquelles elles appelaient de leurs vœux l'évasion du duc. L'accusation ne repose sur rien de tangible, mais montre qu'il n'était guère difficile de faire entrer clandestinement du courrier à Tours. Peut-être les ligueurs avaient-ils aussi songé à faire évader René Le Tourneux, comme le suggère une délibération du corps de ville de février 1592 ordonnant l'expulsion de la ville de la servante du chanoine, avec interdiction d'y revenir "à peine du fouet " pour avoir tenté de lui faire passer des renseignements ${ }^{57}$. Qui étaient les membres de ce réseau clandestin? Jean Despagne, conseiller à la prévôté, ancien conseiller et pair de la ville, dont la présence est attestée en 1591, pourrait en avoir fait partie. Il quitte Tours juste après l'évasion du duc, semble-t-il. Le ralliement de ce dernier à Henri IV en 1594 ne l'incite pas à rentrer dans le rang. Engagé dans l'armée espagnole, il combat en 1595 les troupes françaises aux côtés d'un autre ligueur irréductible, le comte de La Fère. De 1596 à 1600, il vit chichement à Bruxelles avec son épouse, tirant sa subsistance d'une maigre pension que lui verse le roi Philippe II ${ }^{58}$.

Après l'entrée du roi à Paris le 22 mars 1594, la cour et les compagnies souveraines quittent Tours à la mi-avril. Les ligueurs, à première vue, ne constituent plus une menace sérieuse. De fait, un calme relatif revient entre 1594 et 1596. Le retour d'exil des rebelles n'entraîne aucune manifestation d'hostilité. Certains officiers, pour récupérer leurs charges, doivent dédommager les titulaires ${ }^{59}$, mais au final nul ne semble avoir été lésé. L'office de lieutenant général, accordé à Victor Gardette, reste en possession de ce dernier à la suite de la mort opportune de Gilles Duverger en exil $^{60}$. Les ecclésiastiques reprennent aussi leurs fonctions. L'un d'eux, Alexandre Boismartin, négocie en 1595 un arrangement financier à son

56. Annales de Touraine..., op. cit., p. 790-793.

57. BENOIST DE LA GRANDIERE, Louis, op. cit., p. 310.

58. Arch. dép. d'Indre-et-Loire, 3E 9/118 (notaire Foucher), procuration du 8 avril 1591. Descimon, Robert, et Ruiz IBanez, José Javier, Les ligueurs de l'exil. Le refuge catholique français après 1594, Paris, 2005, p. 264 (notice).

59. VALOIS, Noël, Inventaire des arrêts du Conseil d'Etat (règne de Henri IV), t. 1, 1886, p. 45 et 57 (arrêts du 3 mai et du $1^{\text {er }}$ juin 1594 au sujet de Julien Chalopin et Nicolas Joubert, receveurs des tailles), p. 70 (arrêt du 16/7/1594 en faveur d'Adrien Joubert), p. 114 (du 26 novembre 1594 relatif à Cosme Goupil).

60. Ibidem, p. 101 (arrêt de confirmation du 28 octobre 1594). 
avantage avec le chapitre métropolitain au sujet des revenus de sa prébende $^{61}$. Les ligueurs repentis ne sont pas déclassés socialement. En 1595, René Lejeune se fait élire procureur fabricier de la paroisse Saint-Saturnin, preuve que son statut de " coq de paroisse " n'a pas été remis en cause ${ }^{62}$. François Macicault participe régulièrement aux assemblées de Saint-Hilaire, sa paroisse de résidence ${ }^{63}$. En revanche, les élus ayant suivi Duverger en 1588-1589 sont soigneusement tenus à l'écart du pouvoir. Nicolas Joubert, qui avait entamé un cursus municipal avant 1589 (il était conseiller et pair), doit patienter de longues années avant d'être à nouveau autorisé à briguer des fonctions politiques. Il n'accède à l'échevinat qu'en 1613, avant de se faire élire maire en 1616, puis réélire l'année suivante ${ }^{64}$.

L'inquiétude renaît en 1597 à la suite d'une rupture de la trêve entre le roi et le duc de Mercœur. Le 3 avril, le gouverneur fait publier une ordonnance instaurant diverses mesures de défense ${ }^{65}$. Les autorités redoutent des infiltrations de rebelles en ville, où ils pourraient trouver des complicités. Une affaire de libelles clandestins ravive les craintes l'année suivante. Le 10 décembre 1598, Gilles de Souvré charge l'échevin Calais Rogier d'identifier les auteurs de "trois escrictz en forme de lettres missives " ${ }^{66}$ dénonçant l'imposition sur la ville d'une somme de 6000 écus à la "grande charge [et] oppression du peuple affligé ", destinée à financer le voyage du roi en Bretagne. Selon l'auteur anonyme, ce procédé, qui modifiait « l'ordre antien des levées ", avait pour seul but de rendre les habitants taillables. Le gouverneur et le corps de ville ne s'y trompent pas : il s'agit d'une incitation " à sédition contre l'auctorité du Roy et de lad. ville ". La plus longue des lettres, adressée au maire Jean Forget, le complimente dans un premier temps pour son dévouement, avant de l'inciter à s'opposer à la levée. S'il protestait, il serait suivi " de tous les gens de bien qui n'ont ny animosité ny vengeance dans l'ame mais entière affection au bien de leur patrie ". L'expression " gens de bien " pourrait s'appliquer non seulement aux militants de la Ligue, mais plus largement à tous ceux qui, à un moment ou à un autre, ont partagé certaines de leurs vues. En agissant de la sorte, le maire gagnerait " du mérite envers Dieu ». Plus courts, les deux autres écrits s'adressent aux procureurs fabriciers de Saint-Saturnin et de SaintPierre-du-Boile, les appelant à refuser toute collaboration avec les trésoriers de France. L'animosité à l'égard des officiers du bureau des finances est flagrante. Elle est liée, sans doute, aux choix politiques des membres

61. Arch. dép. d'Indre-et-Loire, 3E 2/45 (notaire Patrix), transaction du 22 avril 1595. Il touche 26 écus 7 sols 8 deniers pour les revenus de sa prébende d'août 1589 à juin 1594, déduction faite des frais et taxes acquittés pour lui par les chanoines.

62. Arch. dép. d'Indre-et-Loire, G 1024, p. 9.

63. Par exemple en 1606 : Arch. dép. d'Indre-et-Loire, 3E 5/450 (notaire Coynard), assemblée de Saint-Hilaire, 26 mars 1606.

64. Renseignements aimablement fournis par Claude Petitfrère.

65. Arch. mun. Tours, EE 8, dossier 18 (ordonnance et plusieurs mandements imprimés). 66. Arch. mun. Tours, EE 8, dossier 19 : copie de l'information, de la commission de Souvré et des lettres anonymes. 
de cette compagnie, qui tous intégrèrent le corps de ville épuré de ses éléments ligueurs en 1589. On notera qu'une des lettres fut trouvée dans l'église de Saint-Saturnin sur l'autel de Semblançay, érigé en l'honneur du fameux Jacques de Beaune, baron de Semblançay, pendu en 1527. Faut-il y voir un lien avec l'exécution de six conjurés en août 1589? Tout indique que l'enquête de Rogier n'aboutit pas.

Malgré ces événements, le temps des conjurations est bel et bien révolu. Un rapprochement commence même à s'opérer entre les politiques à la tête de la municipalité et l'ancienne mouvance ligueuse, comme en témoignent les débats soulevés au sujet de l'application de l'édit de Nantes. Le 12 juillet 1599, une délégation d'échevins rencontre les commissaires du roi chargés de l'exécution de l'édit pour dénoncer une requête des députés protestants de Touraine, Anjou et Maine ${ }^{67}$. L'expression utilisée par ces derniers pour désigner leur communauté, " ceux de la religion réformée ", doit être rayée et remplacée par "ceux de la religion prétendue réformée ", exigent les élus : le ton est donné. Le placet des protestants, accusent-ils, contient des contre-vérités scandaleuses au sujet des exactions dont les huguenots prétendent avoir été les victimes au faubourg de La Riche en 1562 et lors de la Saint-Barthélemy. Les délégués contestent aussi les estimations avancées sur le nombre de protestants établis à Tours et fournissent leurs propres chiffres : pas plus de cent soixante ménages, une goutte d'eau dans une ville de plus de " cent mille âmes ${ }^{68}$ ". Enfin, ils refusent l'admission des pauvres et des malades protestants dans les hôpitaux de la ville, sous prétexte que ces institutions sont financées par les dons et legs des catholiques. Le 13 juillet, le corps de ville délibère sur le futur lieu de culte protestant. Les calvinistes souhaitent s'établir à côté du château du Plessis, seul endroit près de Tours (en dehors des faubourgs du cheflieu de bailliage, comme le stipule l'édit de Nantes) relevant du domaine royal, mais les édiles désapprouvent, invoquant des risques de troubles les jours de fête religieuse, lorsque des processions s'ébranlent de la ville vers la collégiale du Plessis ou le couvent des minimes. Leur préférence irait au lieu de la Milletière à Montlouis, à seulement "trois petites lieues " de Tours, qui pourrait aussi servir aux protestants de Montrichard, Bléré, Cormery, Montbazon et Château-Renault ${ }^{69}$. En optant pour la stratégie de l'interprétation a minima de l'édit de Nantes, les édiles font comprendre aux calvinistes qu'ils ne feront rien pour leur faciliter l'existence. Une telle posture ne pouvait que réjouir les catholiques les plus intransigeants. Un nouveau chantier s'ouvre à la fin du siècle, auquel les ennemis d'antan vont

\footnotetext{
67. Arch. mun. Tours, BB 26, $\mathrm{f}^{\circ} 457 \mathrm{r}^{\circ}-460 \mathrm{r}^{\circ}$.

68. Chiffre hautement fantaisiste : à l'époque, la ville ne comptait guère plus de 25000 à 30000 habitants.

69. Arch. mun. Tours, BB 26, $\mathrm{f}^{\circ} 461 \mathrm{r}^{\circ}-462 \mathrm{r}^{\circ}$. C'est finalement au Plessis que sera bâti le temple protestant, les chanoines de la cathédrale s'étant opposés à son implantation hors du faubourg de Saint-Pierre-des-Corps du côté de la rue du Ruau, solution proposée par le Conseil, car l'endroit relevait d'un de leurs fiefs. Arch. mun. Tours, BB 26, f $477 \mathrm{r}^{\circ}-479$ v ${ }^{\circ}$ : délibération du 9 septembre 1599. Le temple sera incendié lors d'une émeute anti-protestante en 1621.
} 
pouvoir collaborer : celui de la reconquête des âmes égarées. Le 14 juillet 1601, l'archevêque de Tours pose solennellement la première pierre du couvent des capucins, à l'issue d'une immense procession qui a conduit les chapitres, les moines et les corps constitués de la cathédrale au nouvel enclos. L'événement suscite un enthousiasme extraordinaire chez tous les catholiques de la ville, réconciliés pour l'occasion ${ }^{70}$.

\section{Prosopographie des ligueurs tourangeaux}

Un corpus de 78 ligueurs a pu être constitué grâce à des sources jusqu'ici peu ou jamais utilisées. Il se limite aux meneurs, à quelques exceptions près. En effet, l'identité des centaines d'émeutiers de la mi-août 1589 échappe aux investigations. Considérés comme peu dangereux sans chefs pour les guider, ils n'ont pas été bannis - à part quelques rares individus - par les autorités, qui n'ont pas non plus jugé bon de les mettre à l'amende ou de faire saisir leurs biens. Implantés à l'ouest de la ville où sont cantonnées les compagnies du sieur de Parabère en 1589-1590, ces sympathisants de la Ligue sont pour la plupart des ouvriers en soie et des artisans modestes. Sur l'île Saint-Jacques, également signalée comme zone d'influence ligueuse, vivent des hommes de peine, des pêcheurs et des voituriers par eau. Pauvres et peu instruits, ces gens se montrent particulièrement réceptifs aux mots d'ordre du clergé et faciles à mobiliser par les notables à la tête du mouvement, qui n'ont qu'à agiter la menace de l'hérétique assoiffé de sang, pillard et sacrilège.

Dans leur grande majorité, les 78 ligueurs identifiés ont dû quitter Tours l'espace de plusieurs années, parfois à titre définitif, pour échapper à la répression, par refus de demeurer dans une ville dominée par un roi calviniste, ou encore pour se conformer à un ordre d'éloignement. Pour être autorisés à revenir, il leur fallut se soumettre à certaines formalités, définies par trois textes officiels. Le premier est la déclaration du roi ou " édit d'abolition " du 28 novembre 1589, qui permet aux ligueurs repentis de regagner leur domicile à condition de prêter serment de fidélité au souverain et de rejet du parti de l'Union ${ }^{71}$. Le deuxième est l'arrêté municipal du 26 décembre 1589 destiné à empêcher le retour d'" aulcuns recongneuz factieulx et gens d'exécution ", qui accorde aux repentis qui se présenteront pleine et entière mainlevée de leurs biens, à condition de faire les " soumissions " exigées par la déclaration royale mais aussi de consentir à un temps d'exil supplémentaire de quelques mois en terre royaliste, à l'issue desquels " ayant donné plus de preuves de leur fidélité ", ils pourront librement regagner leur foyer ${ }^{72}$. Le troisième, tardif (trois retours enregistrés

70. OuRY, Dom Guy, «Le mouvement de restauration catholique en Touraine (1599-1639). $1^{\text {re }}$ partie : 1599-1618 ", dans Église et théologie, 1, Ottawa, 1970, p. 39-59.

71. Arch. nat., $\mathrm{X}^{1 \mathrm{~A}} 8640, \mathrm{f}^{\circ} 86 \mathrm{r}^{\circ}-89 \mathrm{v}^{\circ}$. En 1591, Étienne Bossay se réfère explicitement à ce texte. Arch. mun. Tours, BB 24, $\mathrm{f}^{\circ} 508 \mathrm{r}^{\circ}$ : délibération du 27 mars.

72. Arch. mun. Tours, BB 24, $\mathrm{f}^{\circ} 141 \mathrm{v}^{\circ}$ : délibération du 26 décembre 1589. Au passage, on apprend qu'un rôle (disparu) de tous les habitants " qui auroyent esté mis hors d'icelle " 
avant sa publication), est une ordonnance de Gilles de Souvré du 3 juillet 1591 faisant défense à toute personne de se fixer à Tours sans l'aviser au préalable et obligeant les intéressés à lui indiquer « leurs qualitez, depportemens, affection et fidelité au service de Sa Majesté ${ }^{73}$ ". L'ordonnance précise qu'en attendant une autorisation définitive, les pétionnaires devront résider dans les faubourgs.

La procédure d'admission est la suivante : l'impétrant formule sa demande au gouverneur ou au maire en cas d'indisponibilité. Une enquête est alors diligentée par un ou deux échevins sur ses "déportements " en exil, qui consiste pour l'essentiel à examiner les attestations de bonne conduite fournies par les autorités des lieux où il a séjourné ${ }^{74}$ et à interroger, si possible, les personnes ayant entretenu des rapports avec lui pendant cette période. C'est ainsi que l'on procède avec Barthélemy Gueston, le seul pour lequel on dispose d'une information. Il prétend n'avoir jamais adhéré aux thèses de la Ligue, même s'il a parfois dû donner le change en public, et affirme n'être resté à Paris que pour préserver ses intérêts commerciaux. Les témoignages de marchands l'ayant rencontré avant son retour en 1591 confirment sa version, ou plutôt ne l'infirment pas ${ }^{75}$. Si des doutes subsistent sur la fiabilité d'un individu, un temps de mise à l'épreuve supplémentaire lui est imposé, conformément à la délibération du 26 décembre 1589. Des demandeurs se présentent à l'hôtel de ville certificats à l'appui, après avoir résidé plusieurs mois en des localités situées en zone royaliste : Michel Pasquet (Cormery), René Hache (La Chapelle-Rousselin), Louis Bourgault (Beaumont-lès-Tours) et Louis Lejeune (Luynes). Les délibérations négligent souvent d'indiquer ce lieu, sorte de purgatoire avant l'admission au paradis tourangeau. L'étape suivante est la prestation de serment entre les mains du maire. Le serment exigé est identique à celui prescrit par la déclaration du 28 novembre 1589, à ceci près que l'ancien ligueur doit aussi jurer obéissance au corps de ville. Il ne reste plus qu'à bailler caution. Nulle règle en ce domaine : tout dépend du degré d'implication du demandeur dans le parti de l'Union et surtout de ses facultés. Les sommes, quand elles sont indiquées, s'échelonnent de 200 (André Coullon, fils d'un boucher) à 5000 écus (Urbain Lempereur, marchand bourgeois) ${ }^{76}$. Le compagnon moulinier en soie André Gasnier et le maître joueur d'instrument René Hache en sont dispensés à cause de leur pauvreté. En revanche, on s'explique mal pourquoi l'avocat du roi au présidial Pierre Deméré échappe au versement d'une caution. Entre 1591

[ville] a été établi par le corps de ville à l'intention du Conseil et de Souvré.

73. Arch. mun. Tours, EE 8, dossier 3.

74. Exemple d'un tel document : Arch. dép. d'Indre-et-Loire, 3E 9/120 (notaire Foucher), certificat du 23 décembre 1591 relatif à Louis Bourgault.

75. Arch. mun. Tours, BB 3, dossier 3.

76. Montants connus : 5000 écus (Urbain Lempereur), 2000 écus (Barthélemy Gueston), 1000 écus (Jean Taschereau), 2000 livres (Pierre Delamyne, René Lejeune), 500 écus (Jean Couette, Guillaume Godu, François Macicault), 1000 livres (Urbain Bretonneau), 200 écus (André Coullon). 
et 1593, la municipalité enregistre 18 retours : 5 la première année, 5 la deuxième, 8 la troisième.

En 1594, le contexte politique a changé. La conversion du roi le 25 juillet 1593 et le sacre de Chartres le 27 février 1594 marquent le début d'une longue série de ralliements. Plusieurs villes entament des négociations avec le roi, qui leur octroie des édits de réduction précisant les conditions de leur retour à l'obéissance ${ }^{77}$. Dans la région, Orléans est la première à en bénéficier en février 1594, suivie par Poitiers en juin ${ }^{78}$. Les édits règlent le sort des réfugiés accueillis en ces villes. L'article 20 de l'édit de réduction d'Orléans précise que les personnes " qui se sont retirées des autres villes " pourront retourner d'où elles viennent sans qu'on leur fasse aucune difficulté pour jouir de leurs biens. En fait, les réfugiés n'ont guère le choix, puisque ceux qui refuseraient de tirer parti de l'édit doivent quitter la ville sur-le-champ, les autres bénéficiant d'un délai supplémentaire. L'article 22 de l'édit de réduction de Poitiers, relatif aux réfugiés, est plus laconique : il se contente de leur accorder les mêmes droits que les habitants de la ville. 15 ligueurs reviennent à Tours en 1594, la plupart sinon tous en provenance de ces deux villes ${ }^{79}$. Pour eux, les formalités se limitent à une prestation de serment entre les mains du maire. Le corps de ville tient particulièrement à ce rituel purificatoire : Cosme Goupil et Jean Lemoyne, qui avaient prêté un serment de fidélité au roi et d'" abjuration du party de la Ligue " à Poitiers, doivent recommencer à Tours ${ }^{80}$. Une caution n'est plus exigée, sauf pour Guillaume Godu, mais on ignore s'il venait ou non d'une ville " réduite ${ }^{81}$ ". Le premier à se présenter, Hilaire Duverger, frère de Gilles, reçut une autorisation provisoire de résider valable pour deux mois mais ne jugea pas nécessaire de solliciter par la suite une permission définitive. Pour les suivants, l'autorisation fut délivrée à titre permanent. Le 16 mars 1594, le corps de ville blâme l'élu Pierre Cohu pour s'être réinstallé à Tours sans prêter serment. Il lui ordonne de se présenter à l'hôtel de ville muni de l'arrêt l'autorisant à reprendre ses fonctions à l'élection, mais rien n'indique qu'il ait consenti à se mettre en règle ${ }^{82}$. C'est la limite de la source :

77. CASSAN, Michel, "La réduction des villes ligueuses à l'obéissance ", Nouvelle Revue du Seizième Siècle, 2004, n 22/1, p. 159-174.

78. "Edit du roi sur la réduction de la ville d'Orléans en son obéissance (février 1594)", dans Mémoires de la Ligue contenant les événemens les plus remarquables depuis 1576, jusqu'à la paix accordée entre le roi de France et le roi d'Espagne en 1598, nouv. éd. Amsterdam, Arkstée et Merkus, 1758, 6 volumes, t. 6, p. 58-71. ANDRAUlT, Jean-Pierre, Poitiers à l'âge baroque, 1594-1652. Une capitale de province et son corps de ville, Poitiers, Société des Antiquaires de l'Ouest, 2003, 2 volumes, t. 2, p. 696-702.

79. Sept réfugiés d'Orléans avérés (Bonnier, Pierre Chapelain, Hilaire Duverger, Michel Faverot, Maurice Godu, Nicolas Joubert, Guillaume Landais), deux de Poitiers (Cosme Goupil, Jean Lemoyne).

80. Arch. mun. Tours, BB $25, \mathrm{f}^{\circ} 389 \mathrm{v}^{\circ}$ et $390 \mathrm{r}^{\circ}$ : délibérations du 20/8/1594.

81. Gilles Delamyne, dont la provenance n'est pas non plus spécifiée, obtient d'être dispensé de bailler caution " attendu qu'il est vériffié [qu'il] n'a pas porté les armes ". Arch. mun. Tours, BB 25, $\mathrm{f}^{\circ} 347 \mathrm{r}^{\circ}$ : délibération du 5/3/1594.

82. Arch. mun. Tours, BB $25, \mathrm{f}^{\circ} 350 \mathrm{r}^{\circ}$. 
d'autres individus ont très bien pu imiter Cohu, si bien que l'on ne peut être certain d'avoir répertorié tous les réfugiés. La dernière soumission date du 28 septembre 1594 (retour de Charles Denail).

Une autre source permet de repérer des ligueurs tourangeaux : le Compte unicque de $M^{e}$ Anthoine Damain [...] des deniers provenans de la saisie et vente des biens et revenu de ceulx de la Ligue (1589-1592) ${ }^{83}$. Par lettres patentes du 10 juin 1589 données à Blois, Henri III avait érigé une Chambre du domaine chargée de prononcer les confiscations des biens des individus identifiés comme ligueurs et de les affermer judiciairement, installée à Tours. Elle avait aussi pour tâche de contrôler la comptabilité du receveur Antoine Damain $^{84}$. Elle était composée de 13 membres : deux présidents (Achille de Harlay, premier président du parlement de Paris et Hector de Marle, maître des requêtes), un procureur général, un substitut, un greffier et huit commissaires, dont le trésorier de France César Forget, également échevin de Tours. L'examen du registre montre que le pouvoir royal ne put faire saisir que les biens des rebelles situés dans la partie du Val de Loire qu'il contrôlait : la Touraine, le Vendômois, le Blésois, partiellement l'Anjou et le Maine. Il livre les noms de 21 ligueurs tourangeaux, dont 10 déjà connus pour avoir prêté serment devant le corps de ville entre 1591 et $1594^{85}$. Deux raisons peuvent expliquer le recoupement imparfait des deux sources. D'abord, tous les ligueurs ne sont pas revenus à Tours : certains sont morts en exil, à l'instar de Gilles Duverger et de François Joubert, dont les noms apparaissent dans le Compte unicque, d'autres ont pu décider de recommencer une nouvelle vie ailleurs ou ont fait leur retour à une date tardive, alors qu'une soumission n'était plus requise. Ensuite, seuls les biens des plus riches ont fait l'objet d'une saisie. On n'est guère étonné de ne pas retouver dans le registre le compagnon moulinier en soie André Gasnier ou le teinturier en soie Jean Couette.

Récapitulons : aux 33 ligueurs ayant fait amende honorable devant le corps de ville s'ajoutent 11 individus. Trois autres rebelles sont mentionnés dans les registres de délibérations : deux sont capturés alors qu'ils se dissimulaient en ville. Un autre, soupçonné d'entretenir de mauvais desseins, l'a au contraire quittée pour se réfugier à l'Île-Bouchard ${ }^{86}$. Les 31 noms restants sont tirés de sources diverses : chroniques, arrêts du Parlement et du Conseil ${ }^{87}$.

83. BnF, Nouv. acq. fr. 393, 229 ff.

84. En deux ans et quatre mois (du $1^{\mathrm{er}}$ septembre 1589 au 31 décembre 1591), la recette réalisée fut de 149145 écus 9 sols 8 deniers et la dépense de 153098 écus 27 sols. Les sommes collectées furent pour l'essentiel reversées à différents receveurs pour être employées aux dépenses de guerre. BnF, Ms fr. $10191, \mathrm{f}^{\circ} 112 \mathrm{r}^{\circ}-113 \mathrm{v}^{\circ}$ : " Estat sommaire des receptes et despence du compte rendu par $\mathrm{M}^{\mathrm{e}}$ Anthoine Damain... ", 1589-1591.

85. Alexandre Boismartin, Louis Bourgault, Pierre Cohu (même s'il n'a pas fait sa " soumission » dans les formes), Charles Denail, Hilaire Duverger, Guillaume Godu, Barthélemy Gueston, Nicolas Joubert et Jacques Oudineau.

86. Arch. mun. Tours, BB 24, $\mathrm{f}^{\circ} 524 \mathrm{r}^{\circ}$ : délibération du 15 mai 1591 (capture de Serizier et de Huart); BB 25, $\mathrm{f}^{\circ} 79 \mathrm{r}^{\circ} \mathrm{v}^{\circ}$ : délibération du 8 avril 1592 (René Moreau, réfugié à l'IleBouchard).

87. VAlOIS, Noël, op. cit., t. 1, Paris, Imprimerie nationale, 1886. 
On connaît la profession ou l'état de 66 individus. Les officiers royaux de justice et de finance et les membres du clergé forment près de la moitié de l'effectif (30 individus : 15 officiers et 15 prêtres). Ils sont suivis des marchands et entrepreneurs (13) et des auxiliaires de justice (11). Les catégories populaires sont à peine représentées : seulement 7 artisans indépendants et 5 compagnons. Ces résultats sont assez proches de ceux obtenus par Robert Descimon pour les 225 meneurs de la Ligue parisienne, à ceci près qu'à Tours le poids des auxiliaires de justice est moins important (17\% contre $40 \%$ dans la capitale) ${ }^{88}$. Dans la catégorie des officiers, la forte représentation des magistrats du bailliage et siège présidial de Tours doit être soulignée. Outre le lieutenant général, ont aussi adhéré la Ligue l'avocat du roi Pierre Deméré et quatre juges, auxquels on peut associer le conseiller à la prévôté Jean Despagne. Gilles Duverger exerçait sans nul doute un fort ascendant sur ses collègues, mais cette explication a ses limites. Pour comprendre la radicalisation de certains officiers, il faut remonter aux années 1560, marquées par des querelles violentes entre magistrats catholiques et protestants, les premiers finissant par obtenir le renvoi ou l'éloignement des seconds ${ }^{89}$. Détail intéressant, dès cette époque un troisième groupe d'officiers commence à faire entendre sa voix : celui des catholiques "modérés ", prêts sous certaines conditions à prendre la défense de leurs collègues protestants au nom de l'esprit de corps. Gilles Duverger, alors simple avocat, a sûrement pris parti dans ces affrontements. Ce n'est pas un hasard s'il est pressenti en 1566 pour remplacer le calviniste Gervais Goyet, décédé, en l'office de lieutenant particulier (charge finalement supprimée) ${ }^{90}$. En 1589, la fracture semble profonde entre les deux camps. Des magistrats de premier plan refusent en effet de suivre la ligne préconisée par Duverger et se rangent du côté des politiques : l'ex-lieutenant criminel Victor Gardette, nommé par le roi lieutenant général à la place du chef de la Ligue ${ }^{91}$, le lieutenant particulier Calais Rogier, le nouveau lieutenant criminel Georges Mandat et la majorité des conseillers. La forte implication des auxiliaires de justice dans le mouvement ligueur s'explique-t-elle par un sentiment de frustration des avocats et procureurs, écartés du pouvoir et des honneurs? La thèse, proposée naguère par Henri Drouot $^{92}$, paraît difficilement recevable à Tours. Au contraire, la profession

88. Descimon, Robert, Qui étaient les Seize? Mythes et réalités de la Ligue parisienne (1585-1594), Paris, 1983, p. 230-231.

89. NicholLs, David, "Protestants, Catholics and Magistrates in Tours, 1562-1572 : the Making of a Catholic City during the Religious Wars ", French History, 1994, vol. 8, n 1 , p. 14-33.

90. BnF, Ms fr. $22621, \mathrm{f}^{\circ} 195 \mathrm{v}^{\circ}-196 \mathrm{r}^{\circ}$. De même, Pierre Deméré remplace en 1569 l'avocat du roi Jean Houdry, démis pour cause d'adhésion au protestantisme.

91. C'est lui qui fait lecture au corps de ville de la lettre annonçant l'attentat contre Henri III le 3 août 1589 : Arch. mun. Tours, BB 24, f ${ }^{\circ} 59$ v . À Nantes, en territoire ligueur, les officiers du présidial sont aussi très partagés : LE GALL, Vincent, " Le présidial de Nantes dans la tourmente ligueuse (1589-1598) ", Annales de Bretagne et des Pays de l'Ouest, t. $112, \mathrm{n}^{\circ} 1,2005$, p. $7-31$.

92. Drouot, Henri, Mayenne et la Bourgogne (1587-1596). Contribution à l'histoire des provinces françaises pendant la Ligue, Paris, Picard, 1937, 2 vol. 
d'avocat jouit d'une bonne considération : plusieurs représentants du barreau ont accédé à l'échevinat avant 1589. Quant aux procureurs, certains étaient associés à la prise de décision politique en tant que conseillers et pairs de la ville. Surtout, Gilles Duverger était à même de jouer les conciliateurs entre la robe et la basoche en sa qualité d'ancien auxiliaire de justice. L'histoire des guerres de Religion éclaire, dans une certaine mesure, les choix extrêmistes des membres du clergé. La collégiale de Saint-Martin, à laquelle sept ligueurs sont affiliés ${ }^{93}$, a subi en 1562 des profanations qui ont marqué les esprits. La fureur iconoclaste des troupes de Condé n'épargna pas non plus le couvent des minimes du Plessis, où les restes de saint François de Paule furent jetés au feu ${ }^{94}$. Semblables scènes se produisirent dans plusieurs églises paroissiales, mais la soldatesque s'acharna tout particulièrement sur les couvents des ordres mendiants. La haine cultivée à l'ombre des cloîtres et des chapitres à l'égard des protestants et de tous les "mauvais chrétiens " disposés à les tolérer n'a pas décru au fil des ans et ce ne sont pas quelques arrêts du Parlement qui pouvaient y mettre fin.

En ce qui concerne les marchands, il faut noter que les individus répertoriés se situent au sommet de la hiérarchie urbaine. L'expression " marchand bourgeois " utilisée pour les désigner, les épithètes honorifiques dont les notaires les affublent (" honorable homme ", " honnête personne "), le montant des cautions à verser - 5000 écus pour Jean Taschereau, 2000 pour Barthélemy Gueston - en constituent des preuves indubitables. Il est légitime de s'interroger sur le degré d'engagement de certains. Barthélemy Gueston ne manifeste pas, semble-t-il, un attachement viscéral à la cause ${ }^{95}$. Le jeune Ambroise Aubin, fils d'un marchand, pourrait être dans le même cas : s'il s'est " habitué en la ville de Lyon ", qui entretenait d'étroites relations commerciales avec Tours, il a avant tout agi, semble-t-il, pour le compte de la société paternelle, dont il était le représentant sur place ${ }^{96}$. Les marchands ne sont certes pas tous des tièdes : Guillaume Godu, accusé d'avoir accueilli sous son toit le moine René Marier en 1589, appartenait sans doute à la frange dure de la Ligue tourangelle ${ }^{97}$.

D'autres indices confirment, s'il en était besoin, l'implication des élites dans le mouvement. Il a été possible, à l'aide des actes de baptême des enfants de ligueurs et d'actes notariés de préciser la paroisse de résidence de 25 individus entre 1580 et 1589 : dix sont domiciliés à Saint-Saturnin et sept à Saint-Pierre-le-Puellier, les deux plus opulentes paroisses de la

93. Les vicaires Lemoyne et Tiffame, le chambrier Le Tourneux, les chanoines Bossand, Goussart et Oudineau et un prévôt de Saint-Martin non identifié.

94. Chevalier, Bernard, "La fin d'un grand destin au XvI ${ }^{\mathrm{e}}$ siècle ", dans Histoire de Tours, Toulouse, Privat, 1985, p. 171.

95. L'un des témoins affirme que ce serait un de ses défunts associés, Charles Drouin, qui lui aurait demandé de rester à Paris après la mort du duc de Guise pour "retirer quelque chose " des dettes et marchandises de la société Drouin-Quantin. Arch. mun. Tours, BB 3, information du $1^{\mathrm{er}}$ avril 1591.

96. Arch. mun. Tours, BB 24, f $565 \mathrm{v}^{\circ}$ : délibération du 2 octobre 1591.

97. Palma CAYet, Pierre, op. cit., p. 211. 
cité à l'époque, entre la cathédrale et la collégiale de Saint-Martin. Dans les années 1570-1580, quatre ligueurs ont occupé les fonctions de procureur fabricier de Saint-Saturnin, auxquelles seuls des " manants " riches et estimés pouvaient prétendre : Jean Bergerat (1576-1577), Jean Lucas (1578-1579), Jean Taschereau (1580-1581) et Gilles Duverger (1588). Douze rebelles étaient en charge des affaires de la cité en mai 1589 : le maire, cinq échevins (parmi lesquels trois anciens maires) ${ }^{98}$, le greffier de l'hôtel de ville et au moins cinq pairs et conseillers ${ }^{99}$. Cinq individus (si ce n'est plus) étaient officiers ou sous-officiers de milice bourgeoise : trois capitaines, un lieutenant et un sergent ${ }^{100}$. Ces fonctions éminemment stratégiques les chefs de la milice avaient accès aux arsenaux et disposaient des clés des portes de la ville - étaient elles aussi traditionnellement dévolues aux membres de la sanior pars et aux artisans cossus.

La famille a constitué un cadre privilégié pour le recrutement de nouveaux adeptes. En rejoignant la Ligue, Adrien et Nicolas Joubert ont probablement suivi les traces de leur père, Maurice Godu et Gilles Delamyne également. Avec les frères Joubert, les frères Duverger et Denail font aussi partie du mouvement. L'enquête met en lumière d'autres liens de parenté : le trésorier des turcies et levées Jean Bergerat a pour beau-frère l'ancien receveur des tailles Jean Lucas, tous deux membres du corps de ville, ce dernier étant aussi l'oncle de Jacques Farineau. Guillaume Landais est le beau-père de François Macicault, Pierre Delamyne et François Lichany sont cousins. La question de l'implication des femmes dans la Ligue mérite d'être posée. Si certaines épouses restent à Tours pour veiller sur les intérêts de leurs maris expulsés ou en fuite, comme Michelle Fournier, femme de Jean Bergerat, d'autres les accompagnent en exil : les conjointes de Barthélemy Gueston, Nicolas Joubert et Jean Despagne. Certes, la solidarité avec le mari dans l'épreuve s'inscrit au rang des devoirs fondamentaux de l'épouse et une telle attitude ne saurait être assimilée à un engagement politique. On peut tout de même signaler un cas de participation féminine avérée au mouvement. Françoise Goussart, épouse de Nicolas Joubert, est la seule femme de ligueur dont la Chambre du domaine a prononcé la saisie des biens, au grand scandale du corps de ville d'Orléans (où s'est réfugié le couple), qui adresse en mai 1590 une lettre courroucée au gouverneur et aux maire et échevins de Tours pour s'en plaindre ${ }^{101}$. Même Marie Tergatz, femme de Gilles Duverger, n'avait pas été frappée d'une telle sanction. Par conséquent, il est logique de

98. Jean Bergerat, Étienne Bossay, Julien Chalopin (maire de 1586 à 1587), Pierre Cohu (maire de 1583 à 1585) et Jean Lucas (maire en 1585-1586). Arch. dép. d'Indre-et-Loire, $8 \mathrm{~F} 83 / 7$.

99. Pierre Delamyne, Jean Despagne, Adrien Joubert, Nicolas Joubert et Guillaume Landais.

100. Pierre Deméré, capitaine du quartier de Saint-Pierre-le-Puellier (1588), Gasnay, capitaine (?) de l'île Saint-Jacques (1589), René Lejeune, capitaine de Saint-Saturnin (1588), Guillaume Godu, lieutenant de Saint-Pierre-du-Boile (1585) et Pierre Debonnaire, sergent de bande de La Riche (1588). Arch. mun. Tours, CC 41; Arch. dép. d'Indre-et-Loire, 8F 83/7. 101. BnF, Ms fr. 2945, $\mathrm{f}^{\circ} 90 \mathrm{r}^{\circ} \mathrm{v}^{\circ}$ : lettre du 25 mai 1590. Effectivement, Françoise Goussart est la seule femme mentionnée dans le Compte unicque de 1589-1592. 
penser qu'elle a pris part au complot de mai 1589, puisque c'est à la suite de celui-ci que la confiscation des biens des époux fut prononcée.

Dans cette mouvance ultra-catholique, les liens spirituels revêtent une importance fondamentale. Les parrainages forment un aspect essentiel de ces relations. Gilles Duverger, chef du mouvement, a parrainé deux des enfants de son frère Hilaire, Gilles (1571) et Rachel (1577), ce qui n'étonne pas au sein d'une même famille, mais aussi l'un des fils de François Joubert, Adrien (1563), qui deviendra à l'âge adulte un membre actif de la Ligue. Quant à son épouse Marie Tergatz, elle est marraine en 1566 de Françoise Joubert. Considérons maintenant François Joubert : en 1575, il porte sur les fonts baptismaux un fils d'Hilaire Duverger, prénommé Hilaire comme son père. En 1579, sa femme en fait autant pour une fille d'Hilaire, Rachel. Ces échanges démontrent l'existence de relations étroites entre les deux familles. Les Joubert et les Delamyne sont aussi en excellents termes. François Joubert parraine en 1565 François, fils de Pierre Delamyne. Trois ans plus tard, l'épouse de ce dernier devient la marraine de Charles Joubert. Gilles Duverger fréquente dès les années 1560 d'autres futurs partisans de l'Union. Sa femme est en 1566 la marraine de Jeanne Delamyne et en 1570 de Jean Cohu, fils de l'élu rebelle. En 1572, son fils Esme Duverger a pour parrain le vicaire de Saint-Martin Jean Lemoyne, un des ligueurs exilés. Le cas du receveur des tailles Julien Chalopin ne manque pas d'intérêt. En 1575, il parraine Catherine, fille de l'édile rebelle Jean Lucas - lequel lui rend la pareille cinq ans plus tard avec l'un de ses enfants - et en 1580 Pierre Deméré, fils de l'avocat du roi. Les trois hommes appartenaient au même milieu social, donc rien de surprenant. Cependant, en 1579, Chalopin accepte aussi de parrainer Renée Hache, fille de René, maître joueur d'instrument, autre ligueur. C'est le seul cas avéré de parrainage qui transcende les barrières sociales. Jean Bergerat a parrainé sa nièce Charlotte Lucas en 1571 et à son tour Jean Lucas a porté sur les fonts baptismaux Claude Bergerat en 1575. Entre beaux-frères, ce type d'échange était normal. En dehors de la sphère familiale, Jean Lucas parraine Guillaume Landais le jeune en 1569 (dont la mère est la marraine de Claude, fils de René Lejeune, en 1588), tandis que Jean Bergerat devient en 1588 parrain de Catherine, fille de l'avocat Charles Denail ${ }^{102}$. Gardons-nous d'accorder une importance excessive à ces relations. En effet, l'antagonisme entre ligueurs et politiques n'est tel qu'il pousse à cesser de faire appel à des parrains et marraines de l'autre bord. Pour s'en tenir à un exemple, le 25 octobre 1588, Julien Chalopin s'adresse, pour parrainer son fils Laurent, au trésorier de France Jean Le Blanc, sieur de la Vallière, fidèle parmi les fidèles du dernier Valois

102. Arch. mun. Tours, GG 58 (Saint-Clément), $\mathrm{f}^{\circ} 7 \mathrm{v}^{\circ}-8 \mathrm{r}^{\circ}$; GG 194 (Saint-Pierre-lePuellier), $\mathrm{f}^{\circ} 64 \mathrm{v}^{\circ}, 101 \mathrm{r}^{\circ}, 152 \mathrm{v}^{\circ}, 196 \mathrm{r}^{\circ}, 226 \mathrm{v}^{\circ}, 247 \mathrm{r}^{\circ}$ et $284 \mathrm{v}^{\circ}$; GG 195 (idem), $\mathrm{f}^{\circ} 13 \mathrm{v}^{\circ}, 45 \mathrm{v}^{\circ}$ et $92 \mathrm{v}^{\circ}-93 \mathrm{r}^{\circ}$; GG 196 (idem), $\mathrm{f}^{\circ} 23 \mathrm{r}^{\circ}$ et $32 \mathrm{r}^{\circ}$; GG 217 (Saint-Saturnin), $\mathrm{f}^{\circ} 40 \mathrm{v}^{\circ}, 50 \mathrm{v}^{\circ}-51 \mathrm{r}^{\circ}$,

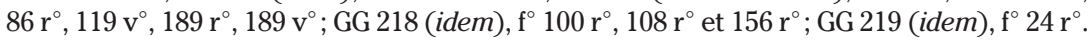


et par la suite serviteur zélé d'Henri IV, dont les réticences à l'égard de la Ligue ne devaient faire de mystère pour personne ${ }^{103}$.

L'existence à Tours d'un mouvement ligueur puissant a longtemps été passée sous silence. Au départ, il s'agissait de faire table rase du passé, suivant la volonté d'Henri IV. Très vite, d'autres considérations sont entrées en ligne de compte : l'espoir d'obtenir ou de conserver certains avantages, la fierté locale aussi. Malgré des pertes documentaires conséquentes, il est possible de reconstituer l'histoire de la Ligue tourangelle et de dresser la liste de ses principaux acteurs, ce que l'on s'est refusé à faire pendant des générations. Puissant est bien le mot, car même après l'échec des conjurations de 1589, la menace d'un coup de force ligueur continue de planer sur la ville jusqu'en 1594 voire 1597. Les provocations verbales perdurent, encouragées par certains représentants du clergé qui ne peuvent se résoudre à reconnaître un roi calviniste. Les militants ultra-catholiques ne se contentent pas de maugréer : ils espionnent, font passer des informations au duc de Mayenne et à ses lieutenants, cachent des individus recherchés, bénéficiant de la complicité plus ou moins active de la population ouvrière des quartiers ouest de la ville. L'action la plus spectaculaire à mettre à leur actif est l'évasion du duc de Guise en 1591. L'opération, un modèle du genre, fut un camouflet retentissant pour le pouvoir royal, même si l'événement n'eut pas de conséquence politique fâcheuse. Contrôlé par une frange de l'élite urbaine composée surtout d'hommes de robe et d'ecclésiastiques, le mouvement ligueur paraît surtout mû par des considérations religieuses. Ce point mérite encore d'être précisé : cela passe par l'étude des testaments et des archives des confréries de dévotion et des compagnies de pénitents, auxquelles de nombreux rebelles, dans le reste du royaume, étaient affiliés ${ }^{104}$. Comme souvent dans la société d'Ancien Régime, les liens professionnels, familiaux et de clientèle ont aussi joué un rôle central.

103. Arch. mun. Tours, GG $219, \mathrm{f}^{\circ} 34 \mathrm{v}^{\circ}$.

104. CASSAN, Michel, Le temps des guerres de Religion. Le cas du Limousin (vers 1530-vers 1630), Paris, Publisud, 1996, p. 124-127. 


\section{RÉSUMÉ}

Pendant les guerres de Religion, les Tourangeaux, souvent présentés de façon caricaturale comme de fervents partisans des rois légitimes, sont en fait profondément divisés. Une part importante de la population soutient la cause des Guises, ce que les autorités locales ont par la suite cherché à occulter. Dès 1584, le parti de l'Union est solidement implanté à Tours, avec à sa tête un fidèle partisan des princes lorrains : le président du siège présidial Gilles Duverger. Par trois fois au cours de l'année 1589, ces "ligueurs de l'intérieur " tentent de prendre le contrôle de la ville. Malgré une sévère répression, l'organisation ne désarme pas : agissant dans la clandestinité à partir de mai 1589, elle reste une menace jusqu'en 1594, voire 1597. C'est ainsi qu'en 1591, le réseau ligueur organise l'évasion du jeune duc de Guise, retenu prisonnier au château de Tours. Régulièrement, les autorités appréhendent des suspects, procèdent à des perquisitions, font traduire en justice des provocateurs, des espions infiltrés et des comploteurs. Grâce à des sources jusqu'ici non exploitées comme les autorisations de réinstallation octroyées par le corps de ville de Tours aux ligueurs repentis et le registre de comptes du fermier des biens des rebelles saisis par le pouvoir royal, il est possible d'identifier les principaux acteurs du mouvement et d'envisager l'étude de ses membres sous l'angle de la prosopographie. Ainsi, les origines sociales, les professions ou fonctions, la situation matrimoniale, les liens de parenté ou de clientèle existant entre les uns et les autres, parfois même le niveau de fortune de ces individus peuvent être mis en lumière : autant d'indications qui permettent de mieux cerner leurs motivations et leur mode opératoire.

\section{ABSTRACT}

During the French Wars of Religion, the people of Tours, often presented - to the point of caricature - as fervent supporters of the lawful kings, were in fact deeply divided. An important part of the population supported the Guises' cause, a fact that local authorities later tried to conceal. Since as early as 1584, the Union had been firmly established in Tours, with a loyal supporter of the princes of Lorraine at its head, Gilles Duverger, the presiding magistrate of the royal tribunal. These "Leaguers from within" tried to take control of the city no fewer than three times during the course of 1589. Despite a harsh repression, the organisation did not relent and became clandestine from May 1589 and it was a force to be reckoned with until 1594 and even 1597. In 1591, for instance, the Leaguers' network was responsible for the escape of the young Duke of Guise held prisoner at the castle in Tours. The authorities regularly arrested suspects, carried out searches, and prosecuted agitators, infiltrators and conspirators. Thanks to sources that had been little used so far, such as permissions granted by the authorities in Tours to reformed leaguers to come back to live in the city, or the account books of the person in charge of the confiscated possessions of the rebels, it is now possible to identify the main participants and set about studying the group from the angle of prosopography. As a result, the social origins, the occupations or positions, the marital status, the family or business links that existed between these people, sometimes even the size of their fortunes can be seen more clearly. These discoveries enable us to have a better understanding of their motivations and of their modus operandi. 